Article

\title{
Study on Extension of Standard Meteorological Data for Cities in South Korea Using ISO 15927-4
}

\author{
Yeweon Kim ${ }^{1}$ * , Hi-Kyoung Jang ${ }^{2}$ and Ki-Hyung $\mathrm{Yu}^{1}$ \\ 1 Building and Urban Research Institute, Korea Institute of Civil Engineering and Building Technology, \\ Ilsan 10223, Korea; raytrace@kict.re.kr \\ 2 Korea Appraisal Board, Daegu 41068, Korea; k25777@kab.co.kr \\ * Correspondence: yeweon.kim@kict.re.kr; Tel.: +82-31-9100-782
}

Received: 18 September 2017; Accepted: 3 November 2017; Published: 14 November 2017

\begin{abstract}
Accurate standard meteorological data sets for each city are essential elements to assess and analyze high-performance buildings quantitatively in order to ensure that they comply with energy saving policies of the nation. ECO2, which is an assessment program of building energy in Korea, has employed meteorological data of the closest city to the target location from 13 urban meteorological data references; the employment of this program has demonstrated the ability to reflect climatic differences between cities. The present study expanded urban meteorological data to ISO TRY (International Organization for Standard Test Reference Year), an international standard methodology that can calculate the data in a relatively simple manner using observed data in Korea, as much as possible in order to reflect meteorological data, including the air temperature relevant for heating and cooling energy as well as solar radiation (cooling/heating energy) for each city, that affected the assessment of building energy the most. In the present study, existing data is expanded to a show the standard meteorological data of 66 cities that can be put into the Korean assessment program (ECO2). This data considered valid meteorological data (minimum statistical period, air temperature, relative humidity, wind, and solar radiation, etc.) among manned and unmanned observational data obtained from 479 locations from 2001 to 2010. For cities other than the 66 aforementioned cities, zoning was conducted to separate cities that had and did not have the standard meteorological data using a cumulative temperature density graph. In this way, meteorological data can be available in all cities, which will enable more accurate simulation assessments on building energy.
\end{abstract}

Keywords: standard meteorological data; assessment of the annual energy use of the building; ISO TRY (Test Reference Year) Method

\section{Introduction}

The Building sector is one of the main energy use sectors, and the ratio of building energy consumption to total energy consumption increased from 33.7\% to $41.1 \%$ between 1980 and 2010 in the U.S. [1]. On a broader scale, the building sector currently accounts for $35 \%$ of the total global energy usage [2]. The Republic of Korea has aimed to reduce its greenhouse gas emissions by $37 \%$ from business-as-usual (BAU) levels by 2030, coinciding with the start of the Paris Agreement that is intended to deal with climate change. Korea has made efforts to reduce energy usage and to improve energy usage efficiency in the operation phase of the building sector [3]. Accordingly, the government in Korea has started rating the energy efficiency of residential and non-residential buildings based on the Building Energy Efficiency Rating System from the Ministry of Trade, Industry and Energy. This has been occurring since 2001 to reduce greenhouse gas emissions in the building sector, which accounts for about $25 \%$ of all emissions in Korea [4-6]. This has strengthened policies regarding improvements on building energy efficiency, including mandatory zero energy in public buildings by 2020 and mandatory zero energy in all buildings by 2025, on pace with the international trend [4-6]. 
South Korea has operated the Building Energy Efficiency Rating System for all new buildings in order to reduce typical building energy, and has evaluated the building energy consumption quantitatively by using the EOC2 program, which is a building energy analysis tool based on DIN18599 used in Germany and ISO 13790 [7-9]. This system calculates a rating based on the primary energy consumption [7-9] due to heating, cooling, hot water, lighting, and ventilation, all of which are required in buildings. Currently, the standard meteorological data used in the EOC2 program refers to meteorological data in 13 typical cities (including Seoul) in Korea, which were distributed by the Korean Solar Energy Society in 2009, which in turn are based on the ISO TRY (International Organization for Standard Test Reference Year) calculation method [10]. However, the data does not reflect the current climate because the data are meteorological data for the past 30 years, and therefore does not account for recent climate change. For example, Seoul, the capital city of Korea, has increased the average temperature of the coldest month by $3{ }^{\circ} \mathrm{C}$, to $-2.4{ }^{\circ} \mathrm{C}$ in recent years, and its climate zone has been changed from $\mathrm{Dw}$ to $\mathrm{Cw}$ in terms of the Koöppen climate classification system since 2009 [11]. The assessment guideline in the Building Energy Efficiency Rating instructs that for locations other than the 13 cities where the standard meteorological data sets are available, the data of the closest city, in terms of distance, should be selected to assess them. The altitude and urban heat island phenomenon in the assessed cities are not reflected, which is why monthly average temperatures are different, even between close cities. For example, Seoul and Paju use the same meteorological data, but their difference in monthly average temperature in winter is $3{ }^{\circ} \mathrm{C}$. With the assessment using this limited meteorological data, the accuracy of the assessments on energy consumption required annually, including cooling and heating energy amounts and consumption in the buildings, may be degraded in energy simulations [12]. A number of methods to generate the typical weather data for locations other than the 13 cities have been widely developed by various researchers for building designs, building systems, and building environment studies: Typical Meteorological Year (TMY), National Renewable Energy Laboratory Typical Metrological Year version 2 (NREL TMY2s) [13-15], International Weather Year for Energy Calculation (IWEC) [16], and Test Reference Year by Europe (TRY) [17], etc. The same calculation technique called the Sandia Method devised by Hall in 1978 is applied to the TMY methodology and NREL TMY2 methodology. This method applies the Fs statistics proposed by the cumulative distribution function (CDF) for every meteorological element to select a candidate year, thereby calculating an absolute difference between the long-term CDF and short-term CDF distribution for each year for the calculation period. Afterward, a weight for each calculation method is applied to calculate a sum for the meteorological elements, thereby selecting five candidate years whose sum is the least. Then, ranks of the values whose difference between the long-term mean and long-term median of the long-term data and the selected five candidate years are determined. It is a method to select final representative years by eliminating years that include frequencies and duration of the days of lower than $33 \%$ of global horizontal irradiance (GHI) and above $67 \%$ and lower than $33 \%$ of the average dry air temperature. The NREL TMY2 has the same procedure with that of TMY, but it adds the direct normal irradiance, thereby applying 50\% weight of the global horizontal irradiance (GHI) by $25 \%$, respectively. For IWEC its procedure and applied data are the same as those with the IWEC method TMY published by ASHRAE in 2002 but it uses a method that expands a weight of the average air temperature from about $8.3 \%$ to $30 \%$ and minimizes a weight of wind speed. In ISO 15927-4 (proposed in 2005), primary meteorological elements such as air temperature, relative humidity, and global horizontal irradiance (GHI) as well as secondary meteorological elements such as average wind speed are used. Here, no weights for meteorological elements are applied. Regarding these various calculation methods, Yoo et al. (2012) [18] reported that most calculation methods using a weight employed weights of air temperature and solar radiation, which accounted for $60 \%$ to $80 \%$ of all weight using methods, and that applied meteorological elements were also similar. However, the results of the standard years calculated by simple calculation methods such as TRY and air temperature and horizontal solar radiation of measured data showed more than a significance level of $99 \%$, the same as other methodologies, and a significance level of mean wind speed showed the 
most similarity of $0.8 \%$. Thus, it would be advantageous to produce standard meteorological data through ISO TRY, which can produce data simply in the relative sense. Thus, these were designed in order to overcome the limitation of meteorological data in regard to the regional characteristics and the most up-to-date meteorological data not being reflected. The present paper extended the standard meteorological data for cities as much as possible using the ISO 15927-4 [19] methodology from the existing standard meteorological data of 13 representative cities. Thus, the main purpose of this study was to utilize the Korean weather data as foundational data for building energy assessment by breaking down and expanding the Korean weather data as much as possible-a difficult task given that the annual range is large and the temperature difference varies between north and south regions and between east and west regions as a result of the significant influence of the Eurasian continent due to the geographical characteristics associated with Korea's location on the eastern shore of the Eurasian continent.

\section{Study Method and Procedure}

The present study aims to develop extended standard urban meteorological data based on raw meteorological data recorded at the observatories in Korea. The study procedure to accomplish this is as follows: First, regions that have valid values of meteorological parameters for a statistical period of more than 10 years according to the methodology are extracted as raw data. The required meteorological elements are in accordance with ISO15927-4 methodology, from manned and unmanned meteorological observations in Korea. Second, the data collection period is set to the longest statistical period, which is from 2001 to 2010 (10 years), and the meteorological data that is produced using the derivation method of meteorological reference year is provided by ISO 15927-4. Sixty-six cities satisfy the period condition suggested by the methodology. Third, for cities without horizontal global insolation data among the standard meteorological data of the 66 cities created by ISO 15927-4, global horizontal irradiance (GHI) values of cities where GHI data is available among the closest cities with that data available are used. Fourth, similar climate regions are zoned using the cumulative temperature density graph pattern with adjacent regions for si (cities), gun (counties), and gu (districts) in Korea, and the assessments of the cities and regions outside the 66 cities are conducted by interlinking the standard meteorological data of the 66 cities.

\section{Construction of the Standard Meteorological Data}

\subsection{Securing Meteorological Data}

The present study secured meteorological data of 46 regions, including 45 representative land regions and one Jeju region (southernmost island in Korea) from the Korea Meteorological Administration (KMA) for the 30-year period from 1981-2010. Then the raw data of the meteorological parameters, such as wind direction, wind speed, insolation, and quantity of horizontal solar radiation, air temperature, dew point temperature, and relative humidity, were investigated. Data that had only air temperature or did not satisfy the minimum valid period, which was a consecutive period of 10 years, due to a short measurement period, from either manned and unmanned measured meteorological data at any of the 527 regions recorded by the KMA were excluded [11]. The investigation results for the raw data between 2001 and 2010 among urban data in the 66 cities where valid meteorological data was available within the period showed that an omission data ratio of meteorological parameters such as air temperature, relative humidity, wind speed, dew point temperature, and wind direction was $0-0.01 \%$ on average, which was still found to be valid for processing as standard meteorological data. In contrast, horizontal global insolation data were measured at only 20 out of 66 cities, and the result of analysis of the data showed its omission data ratio of horizontal GHI and sunshine was $17.9 \%$ on average, which was higher than that of the other meteorological parameters. However, this data omission was due to the omission of sun rise and sunset times. Thus, this data is considered valid for processing as standard meteorological data. 


\subsection{Data Production Procedure}

The difference in methodologies of how to produce standard meteorological data can be divided according to the meteorological parameters to be considered, the importance per parameter, the selection procedure of the reference year, and the selection method of the final data [18]. Furthermore, studies on the comparison of production methods for standard meteorological data reported that although a ratio of weight per meteorological parameters was important, the selection procedure affected the data more significantly [18]. Although it is ideal to apply a production method that suits each city by considering the climate characteristics of that city, air temperature and GHI were more influential on the cooling and heating load in energy assessment than the other factors. The reason for the important role of air temperature, GHI, and humidity building energy consumption was because the building energy requirement is calculated by a sum of envelope conduction heat loss, which is a loss due to temperature difference between outdoor and indoor environments, loss due to ventilation heat loss, heat generation acquisition from internal equipment and human bodies, and acquisition due to GHI. Furthermore, for the Korean climate, which is characterized by high temperature and humidity in summer, since a latent heat load is also calculated during the facility load calculation to compute energy consumption, humidity is an essential element for energy consumption calculation. Difference in the average load compared to the result of a single year according to the standard meteorological data methodology was insignificant according to a study on the comparison of cooling and heating loads by a production model. Thus, the present study employed ISO TRY (ISO 15927-4) [15], which can be produced easily, to extend urban meteorological data [20]. In ISO 15972-4, best years are selected through air temperature, global horizontal irradiance, and relative humidity as the primary data, and final standard years are selected through mean wind speed with regard to three candidate years. This is because these are the key parameters for cooling and heating calculation. There are no weights for meteorological elements applied in ISO TRY, and the manner used to select standard years is as follows:

Step 1-Daily average values of the metrological parameters (air temperature, relative humidity, and GHI) per hour are calculated for the 10-year time series.

Step 2-All monthly values for the entire statistical period are sorted in ascending order, and then using the cumulative distribution function $(\mathrm{CDF})$, a daily average cumulative distribution function for the entire statistical period is calculated (long-term CDF).

$$
\Phi(p, m, I)=\frac{K(i)}{N+1}
$$

$p$ : Air temperature $\left({ }^{\circ} \mathrm{C}\right)$.

$m$ : Relative humidity (\%).

I: Global horizontal irradiance $\left(\mathrm{MJ} / \mathrm{m}^{2}\right)$.

$K(i)$ : Rank of the daily average $i$ value that corresponds to a month among the data in the entire statistical period.

$N$ : Number of days in a month among the data in the entire statistical period.

Step 3-All values of each year that correspond to one month among the data in the entire statistical period are arranged in descending order, and then the daily average CDF for each year in each month is calculated through the following equation (short-term CDF).

$$
F(p, y, m, I)=\frac{J(i)}{n+1}
$$

F: Daily average CDF in each month.

$J(i)$ : Rank of daily average $i$ value of the year that corresponds to each month out of the entire statistical period.

$n$ : Number of days in the year that correspond to each month out of the entire statistical period.

Step $4-F s(p, y, m)$ is calculated through the Factor Security $(F s)$ statistics to compare the long-term and short-term CDF for each month. 


$$
F_{S}(p, y, m)=\sum_{i=1}^{n}|F(p, y, m, I)-\Phi(p, m, I)|
$$

Fs: absolute value between long-term CDF for the entire calculation period and short-term CDF for each year.

$\Phi$ : Daily average CDF during the entire statistical period.

Step 5-A rank of an $F s(p, y, m)$ value for each month is arranged in descending order, and then three meteorological parameters (air temperature, relative humidity, and GHI) are arranged by year for each month, followed by a summation of the ranks. The three lowest totals are selected as three candidate days, and an average value of wind speed data for the year that corresponds to the month is calculated. Then, the mean of all wind speed data within the entire statistical period that corresponds to the month is calculated, and a deviation with the previously calculated mean value is calculated. To select the representative month among three candidate months, the month that had the least deviation of the mean is indicated as being the "best", and is used as the representative month.

Step 6-Meteorological parameters during the last eight hours in each month and meteorological parameters during the first eight hours in the next month are connected smoothly to combine the representative month with the virtual year. Furthermore, compensation work including the last eight hours in December and the first eight hours in January of the next year should also be performed to employ the reference year iteratively in the simulation.

\subsection{Construction of Standard Meteorological Data}

Figure 1 shows graphs of the long-term CDF (2001-2010) of air temperature, relative humidity, and horizontal global insolation in Seoul during January according to the previous production method and procedure, and the short-term CDF by year. The $F s$ values were calculated using Fs statistics to compare the long-term and the short-term CDFs accurately. Accordingly, a rank for each of the three meteorological parameters was summed, and years 2003, 2004, and 2006 were selected as candidate months for Seoul.

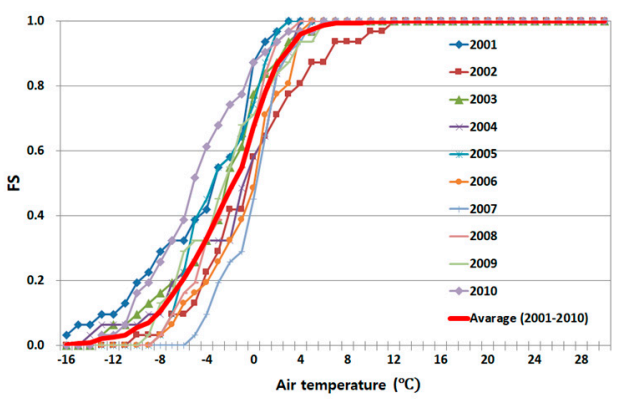

(a)

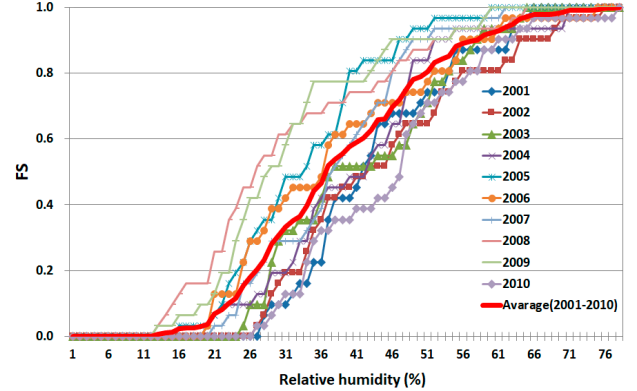

(b)

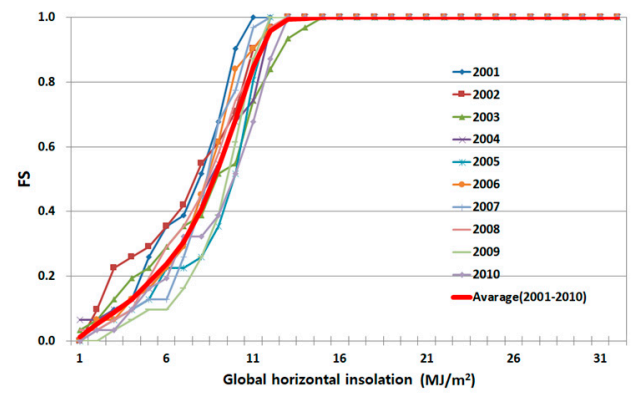

(c)

Figure 1. Comparison of yearly Fs values, considering a difference between long-term and short-term CDF values. (Seoul, January); (a) Air temperature; (b) Global horizontal insolation; (c) Relative humidity. 
Then the mean wind speed for each of the candidate months and the mean value of wind speed data during the entire statistical period were calculated, and a deviation between the mean values was calculated. Table 1 presents the results of Figure 1, in which Fs values and ranks concerning three weather data values are presented. Table 2 presents the deviations, and January in 2004, which was selected as the representative month because its deviation was the least of the candidate months, at 0.06 .

Similarly, the other months (February to December) and 65 other regions outside Seoul were statistically processed. Table 3 presents the monthly reference years determined for 66 regions.

Table 1. Factor Security $(F s)$ values and rankings for each of the three meteorological parameters (Seoul, January).

\begin{tabular}{ccccccccccc}
\hline Meteorological Parameter & $\mathbf{2 0 0 1}$ & $\mathbf{2 0 0 2}$ & $\mathbf{2 0 0 3}$ & $\mathbf{2 0 0 4}$ & $\mathbf{2 0 0 5}$ & $\mathbf{2 0 0 6}$ & $\mathbf{2 0 0 7}$ & $\mathbf{2 0 0 8}$ & $\mathbf{2 0 0 9}$ & $\mathbf{2 0 1 0}$ \\
\hline Air Temperature & 2.34 & 2.08 & 0.72 & 0.94 & 1.41 & 1.71 & 2.34 & 0.79 & 0.83 & 2.59 \\
Ranking & 9 & 7 & 1 & 4 & 5 & 6 & 8 & 2 & 3 & 10 \\
Relative Humidity & 4.99 & 6.01 & 2.36 & 3.08 & 5.30 & 2.27 & 2.71 & 7.53 & 7.49 & 6.93 \\
Ranking & 5 & 7 & 4 & 3 & 6 & 1 & 2 & 10 & 9 & 8 \\
Insolation & 0.99 & 0.99 & 0.77 & 0.31 & 0.81 & 0.45 & 0.72 & 0.38 & 1.00 & 0.86 \\
Ranking & 9 & 8 & 5 & 1 & 6 & 3 & 4 & 2 & 10 & 7 \\
Total Sum of Rankings & 23 & 22 & 10 & 8 & 17 & 10 & 14 & 14 & 22 & 25 \\
Ranking & 9 & 7 & 2 & 1 & 6 & 2 & 4 & 4 & 7 & 10 \\
\hline
\end{tabular}

Table 2. Wind velocity data for January as a representative month (Seoul).

\begin{tabular}{cccccc}
\hline $\begin{array}{c}\text { Candidate } \\
\text { Month }\end{array}$ & $\begin{array}{c}\text { Mean Wind } \\
\text { Speed }\end{array}$ & $\begin{array}{c}\text { Mean Wind Speed of the } \\
\text { Entire Statistical Period }\end{array}$ & $\begin{array}{c}\text { Absolute } \\
\text { Deviation }\end{array}$ & Ranking & Representative Month of January \\
\hline 2003 & 2.00 & & 0.29 & 3 & \\
2004 & 2.35 & 2.30 & 0.06 & 1 & 2004 (BEST) \\
2006 & 2.37 & & 0.07 & 2 & \\
\hline
\end{tabular}

A value of GHI during the assessment on building energy is highly relevant in calculating the required building energy value. Thus, it is important to set up a GHI value that reduces the error range as much as possible for regions where GHI was not measured when building energy values are calculated in the 66 regions in Korea. Since measured GHI data in Korea was lacking, the same insolation in the closest region (20 cities) where insolation data was available was applied to the other 46 regions where GHI was not measured. The result of the process is shown in Figure 2, and is also summarized in Table 3. Note that this methodology has several limitations. First, it cannot provide accurate solar radiation data for all regions because it draws solar radiation of adjacent city based on the assumption that a difference in solar radiation between regions except for regions of lowest (Seoul: 4144) and highest (Mokpo: 5110) solar radiation was not so significant (mean: 4760). Regarding this assumption, when the 1D linear interpolation methodology was used for the investigation, the solar radiation of Daejeon, located between Seoul and Mokpo, was 4707 (actual solar radiation was 4820), which revealed approximately a $2.3 \%$ difference. Second, for urban regions, there is a need to consider how solar radiation and temperature affect buildings according to height and density of high-rise buildings. Nonetheless, this study method has a limited ability to consider a spatio-temporal structure such as urban heat island. Thus, for future studies, a study on solar radiation and artificial heat source for urban regions is needed for more detailed assessment. Despite these limitations, it provides a solar radiation value similarly to each of the expanded regions according to the characteristics of the current $\mathrm{ECO} 2$ assessment program and its role is limited to providing data values based on the assumption that no significant effect is exerted on adjacent buildings around the building in metropolitan cities. 


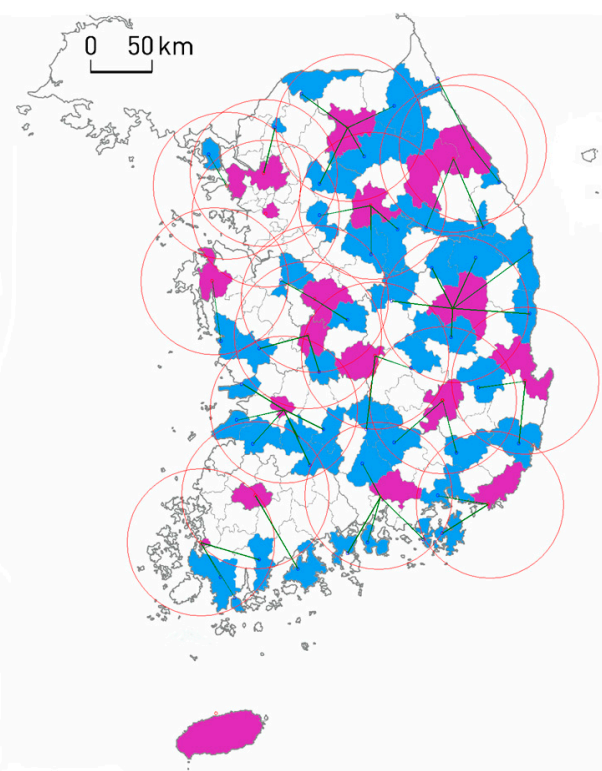

Figure 2. Global horizontal irradiance (GHI) setup method (pink: with insolation gain; blue: without insolation gain).

Table 3. Establishment of standard meteorological data for 66 regions.

\begin{tabular}{|c|c|c|c|c|c|c|c|c|c|c|c|c|}
\hline Region & Jan. & Feb. & Mar. & Apr. & May & June & July & Aug. & Sept. & Oct. & Nov. & Dec. \\
\hline Suwon & 2003 & 2003 & 2003 & 2001 & 2001 & 2009 & 2003 & 2001 & 2001 & 2003 & 2008 & 2003 \\
\hline Chuncheon & 2004 & 2010 & 2003 & 2001 & 2009 & 2009 & 2001 & 2009 & 2003 & 2009 & 2009 & 2003 \\
\hline Wonju & 2008 & 2002 & 2008 & 2008 & 2008 & 2004 & 2008 & 2008 & 2004 & 2008 & 2008 & 2008 \\
\hline Gangneung & 2002 & 2006 & 2001 & 2001 & 2006 & 2001 & 2001 & 2001 & 2001 & 2007 & 2001 & 2006 \\
\hline Daegwallyeong & 2001 & 2001 & 2001 & 2001 & 2003 & 2001 & 2004 & 2001 & 2003 & 2010 & 2010 & 2010 \\
\hline Cheongju & 2001 & 2001 & 2001 & 2004 & 2007 & 2007 & 2004 & 2004 & 2001 & 2004 & 2004 & 2006 \\
\hline Chupungnyeong & 2008 & 2009 & 2009 & 2008 & 2004 & 2009 & 2009 & 2004 & 2003 & 2004 & 2008 & 2008 \\
\hline Seosan & 2009 & 2006 & 2009 & 2007 & 2007 & 2007 & 2004 & 2009 & 2006 & 2009 & 2004 & 2008 \\
\hline Jeonju & 2010 & 2006 & 2006 & 2004 & 2010 & 2006 & 2010 & 2010 & 2002 & 2010 & 2004 & 2006 \\
\hline Mokpo & 2002 & 2006 & 2006 & 2007 & 2003 & 2006 & 2006 & 2005 & 2002 & 2005 & 2006 & 2002 \\
\hline Pohang & 2004 & 2006 & 2003 & 2003 & 2003 & 2003 & 2005 & 2004 & 2004 & 2004 & 2004 & 2003 \\
\hline Andong & 2004 & 2002 & 2002 & 2002 & 2010 & 2002 & 2002 & 2004 & 2002 & 2010 & 2002 & 2009 \\
\hline Jinju & 2009 & 2009 & 2004 & 2004 & 2003 & 2006 & 2007 & 2009 & 2009 & 2010 & 2008 & 2008 \\
\hline Jeju & 2001 & 2001 & 2006 & 2007 & 2010 & 2007 & 2010 & 2006 & 2001 & 2007 & 2001 & 2002 \\
\hline Seoul & 2004 & 2004 & 2006 & 2004 & 2006 & 2006 & 2007 & 2004 & 2004 & 2004 & 2006 & 2004 \\
\hline Busan & 2007 & 2003 & 2007 & 2007 & 2010 & 2007 & 2007 & 2009 & 2009 & 2010 & 2007 & 2009 \\
\hline Daegu & 2004 & 2003 & 2007 & 2007 & 2007 & 2004 & 2007 & 2007 & 2003 & 2007 & 2007 & 2003 \\
\hline Incheon & 2008 & 2002 & 2004 & 2007 & 2007 & 2007 & 2007 & 2007 & 2002 & 2007 & 2007 & 2008 \\
\hline Gwangju & 2009 & 2003 & 2009 & 2005 & 2005 & 2009 & 2005 & 2009 & 2009 & 2005 & 2005 & 2009 \\
\hline Daejeon & 2007 & 2006 & 2007 & 2005 & 2007 & 2007 & 2007 & 2007 & 2007 & 2008 & 2008 & 2008 \\
\hline Ganghwa & 2004 & 2002 & 2004 & 2002 & 2002 & 2002 & 2002 & 2004 & 2002 & 2004 & 2004 & 2002 \\
\hline Sokcho & 2008 & 2008 & 2008 & 2007 & 2008 & 2010 & 2007 & 2008 & 2010 & 2008 & 2008 & 2008 \\
\hline Hongcheon & 2006 & 2006 & 2003 & 2006 & 2006 & 2006 & 2004 & 2004 & 2006 & 2004 & 2006 & 2006 \\
\hline Buyeo & 2009 & 2004 & 2007 & 2004 & 2004 & 2007 & 2007 & 2004 & 2004 & 2004 & 2009 & 2009 \\
\hline Geumsan & 2004 & 2002 & 2006 & 2001 & 2002 & 2002 & 2002 & 2002 & 2001 & 2002 & 2006 & 2002 \\
\hline Cheonan & 2004 & 2006 & 2004 & 2004 & 2007 & 2004 & 2004 & 2006 & 2004 & 2004 & 2006 & 2006 \\
\hline Boryeong & 2009 & 2010 & 2010 & 2007 & 2010 & 2006 & 2006 & 2006 & 2007 & 2010 & 2010 & 2010 \\
\hline Boeun & 2006 & 2006 & 2006 & 2005 & 2004 & 2006 & 2005 & 2005 & 2002 & 2004 & 2005 & 2002 \\
\hline Jecheon & 2008 & 2010 & 2009 & 2008 & 2009 & 2009 & 2010 & 2009 & 2009 & 2010 & 2010 & 2010 \\
\hline Yeosu & 2009 & 2009 & 2009 & 2007 & 2009 & 2009 & 2009 & 2009 & 2009 & 2009 & 2007 & 2009 \\
\hline Wando & 2001 & 2002 & 2001 & 2002 & 2001 & 2002 & 2002 & 2001 & 2002 & 2001 & 2001 & 2002 \\
\hline Jangheung & 2007 & 2003 & 2004 & 2005 & 2005 & 2005 & 2005 & 2005 & 2003 & 2005 & 2005 & 2002 \\
\hline Haenam & 2009 & 2002 & 2002 & 2002 & 2002 & 2001 & 2002 & 2009 & 2001 & 2009 & 2009 & 2002 \\
\hline Goheung & 2004 & 2004 & 2004 & 2004 & 2010 & 2004 & 2005 & 2004 & 2004 & 2004 & 2007 & 2004 \\
\hline
\end{tabular}


Table 3. Cont.

\begin{tabular}{|c|c|c|c|c|c|c|c|c|c|c|c|c|}
\hline Region & Jan. & Feb. & Mar. & Apr. & May & June & July & Aug. & Sept. & Oct. & Nov. & Dec. \\
\hline Jeongeup & 2004 & 2006 & 2006 & 2006 & 2006 & 2006 & 2002 & 2006 & 2001 & 2007 & 2006 & 2006 \\
\hline Buan & 2006 & 2006 & 2006 & 2007 & 2006 & 2006 & 2007 & 2005 & 2007 & 2007 & 2007 & 2002 \\
\hline Ulsan & 2003 & 2006 & 2007 & 2007 & 2007 & 2007 & 2007 & 2003 & 2007 & 2007 & 2007 & 2003 \\
\hline Miryang & 2007 & 2001 & 2007 & 2001 & 2001 & 2002 & 2002 & 2001 & 2001 & 2004 & 2007 & 2004 \\
\hline Geochang & 2005 & 2001 & 2001 & 2007 & 2001 & 2001 & 2007 & 2005 & 2001 & 2005 & 2007 & 2001 \\
\hline Sancheong & 2008 & 2006 & 2002 & 2008 & 2008 & 2006 & 2002 & 2008 & 2002 & 2010 & 2008 & 2008 \\
\hline Hapcheon & 2005 & 2002 & 2005 & 2002 & 2002 & 2002 & 2002 & 2002 & 2002 & 2005 & 2005 & 2002 \\
\hline Namhae & 2005 & 2007 & 2007 & 2005 & 2005 & 2005 & 2005 & 2005 & 2005 & 2005 & 2005 & 2002 \\
\hline Uljin & 2009 & 2001 & 2001 & 2002 & 2002 & 2007 & 2002 & 2001 & 2001 & 2007 & 2007 & 2002 \\
\hline Yeongju & 2001 & 2001 & 2001 & 2001 & 2007 & 2001 & 2001 & 2001 & 2001 & 2001 & 2007 & 2010 \\
\hline Mungyeong & 2004 & 2004 & 2004 & 2008 & 2004 & 2008 & 2004 & 2004 & 2004 & 2004 & 2008 & 2008 \\
\hline Uiseong & 2006 & 2006 & 2004 & 2004 & 2006 & 2006 & 2004 & 2004 & 2004 & 2007 & 2007 & 2006 \\
\hline Gumi & 2007 & 2006 & 2007 & 2007 & 2007 & 2006 & 2005 & 2007 & 2007 & 2007 & 2007 & 2006 \\
\hline Yeongdeok & 2008 & 2010 & 2003 & 2003 & 2010 & 2004 & 2005 & 2005 & 2004 & 2004 & 2010 & 2004 \\
\hline Yeongcheon & 2004 & 2001 & 2004 & 2002 & 2004 & 2004 & 2002 & 2001 & 2001 & 2004 & 2005 & 2002 \\
\hline Geoje & 2001 & 2001 & 2001 & 2001 & 2007 & 2001 & 2001 & 2001 & 2001 & 2007 & 2007 & 2002 \\
\hline Gunsan & 2004 & 2006 & 2006 & 2006 & 2007 & 2006 & 2006 & 2004 & 2004 & 2004 & 2004 & 2006 \\
\hline Namwon & 2004 & 2006 & 2006 & 2006 & 2007 & 2010 & 2006 & 2004 & 2004 & 2007 & 2004 & 2006 \\
\hline Dongducheon & 2009 & 2006 & 2007 & 2001 & 2007 & 2004 & 2008 & 2008 & 2001 & 2007 & 2007 & 2006 \\
\hline Donghae & 2009 & 2001 & 2001 & 2003 & 2001 & 2001 & 2001 & 2001 & 2005 & 2001 & 2003 & 2003 \\
\hline Bonghwa & 2004 & 2006 & 2006 & 2006 & 2006 & 2006 & 2002 & 2006 & 2004 & 2005 & 2006 & 2006 \\
\hline Yangpyeong & 2004 & 2004 & 2004 & 2006 & 2004 & 2004 & 2004 & 2004 & 2004 & 2004 & 2004 & 2006 \\
\hline Yeongwol & 2008 & 2002 & 2006 & 2002 & 2006 & 2008 & 2009 & 2008 & 2006 & 2008 & 2008 & 2002 \\
\hline Icheon & 2005 & 2010 & 2008 & 2008 & 2005 & 2008 & 2008 & 2005 & 2003 & 2005 & 2008 & 2008 \\
\hline Inje & 2004 & 2004 & 2004 & 2004 & 2004 & 2004 & 2004 & 2004 & 2004 & 2010 & 2009 & 2010 \\
\hline Imsil & 2001 & 2001 & 2007 & 2007 & 2007 & 2007 & 2002 & 2001 & 2007 & 2007 & 2001 & 2002 \\
\hline Jangsu & 2004 & 2004 & 2004 & 2004 & 2006 & 2004 & 2004 & 2004 & 2004 & 2004 & 2008 & 2002 \\
\hline Changwon & 2009 & 2009 & 2009 & 2001 & 2009 & 2009 & 2009 & 2001 & 2001 & 2009 & 2001 & 2009 \\
\hline Cheorwon & 2008 & 2006 & 2008 & 2007 & 2010 & 2006 & 2002 & 2008 & 2006 & 2010 & 2008 & 2010 \\
\hline Chungju & 2004 & 2002 & 2004 & 2002 & 2004 & 2008 & 2004 & 2004 & 2009 & 2004 & 2005 & 2002 \\
\hline Taebaek & 2006 & 2007 & 2007 & 2007 & 2007 & 2007 & 2007 & 2007 & 2007 & 2007 & 2007 & 2007 \\
\hline Tongyeong & 2008 & 2001 & 2001 & 2007 & 2008 & 2001 & 2007 & 2001 & 2001 & 2007 & 2007 & 2008 \\
\hline
\end{tabular}

\subsection{Derivation of Similar Climate Zone}

A representative single meteorological data point should be selected to evaluate building energy in a region where buildings are constructed. Thus, si, gun, and gu in Korea should be zoned with regard to the 66 cities where the standard meteorological data was constructed by using the process detailed in the previous sections.

The administrative divisions in South Korea consist of one special city (Seoul), one special self-governing city (Sejong), six metropolitan cities (Incheon, Gwangju, Daegu, Daejeon, Ulsan, and Busan), eight provinces (Gangwon-do, Gyeonggi-do, Gyeongsangbuk-do, Gyeongsangnam-do, Jeollabuk-do, Jeollanam-do, Chungcheongbuk-do, and Chungcheongnam-do), and one special self-governing province (Jeju-do). On a smaller scale, the administrative divisions include 74 si (cities), 84 gun (counties), and $69 \mathrm{gu}$ (districts), which result in $227 \mathrm{si}$, gun, and gu in total (excluding administrative city and self-governing gu) [21].

In this study, si-gun-gu were set to the minimum unit of the similar climate zone. In 161 out of $227 \mathrm{si}$, gun, and gu (71\% of all si, gu, and gu in Korea) temperature data was recorded and the $227 \mathrm{si}$, gun, and gu were zoned. Eight do (provinces), one special city (Seoul), one special self-governing city (Sejong), and five metropolitan cities, excluding Incheon metropolitan city, (Gwangju, Daegu, Daejeon, Ulsan, and Busan) were set as a single zone. For similar climate zoning of a total of 161 si-gun-gu regions within the 66 regions of the standard meteorological data, hourly air temperature data from 2012 (one year) was obtained from the KMA. Data for 95 out of the 161 cities, excluding 66 cities where the standard meteorological data was already created, was obtained by unmanned observation. Among the regions, there are 86 regions where currently measured data is available (just air temperature), and the other nine regions had no available data. Thus, the regions where the 
air temperature data was not available were set to employ the air temperature and the meteorological data of the adjacent regions, as presented in Table 4.

Table 4. Matching of nine regions where air temperature is not measured with similar regions using cumulative density function.

\begin{tabular}{cc}
\hline Secured Region & Air Temperature Setup in the Unsecured Regions (As of 2012) \\
\hline Guri & Hanam \\
Gwacheon & Bucheon, Gwangmyeong, Anyang, Gunpo, Uiwang \\
Ganghwa & Gimpo \\
Dongducheon & Paju \\
Daejeon & Okcheon \\
\hline
\end{tabular}

For zoning of the 86 regions where data was measured by unmanned observations within the 66 regions where the standard meteorological data was actually measured, cumulative temperature density data (compared to 10-year hourly mean air temperature data) at the unmanned observation regions were compared with that of the standard meteorological data in the closest region, thereby matching two cities where the least difference was found. For example, Figure 3 presented graph of cumulative temperature density at Yangyang and Danyang, which were two comparative cities, showed that Yangyang had the most similar temperature zone with that of "Sockcho" (Fs value: 0.3) compared with other adjacent regions (Gangneung, Pyeongchang, Inje, and Hongcheon). Similarly, the analysis results showed that Danyang formed the most similar climate zone with that of "Youngwol" (Fs value: 0.3 ).

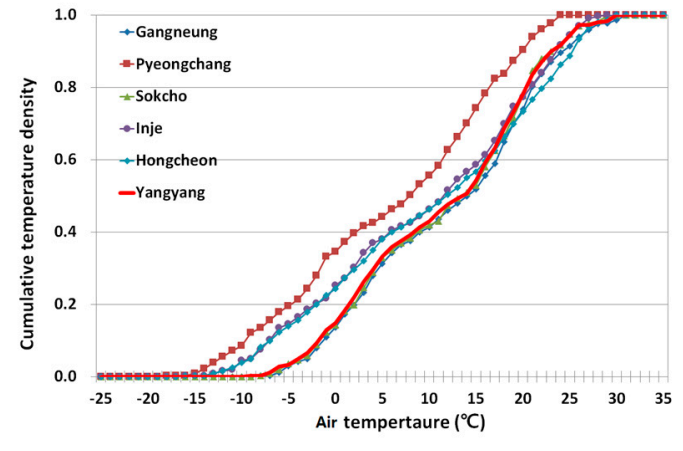

(a)

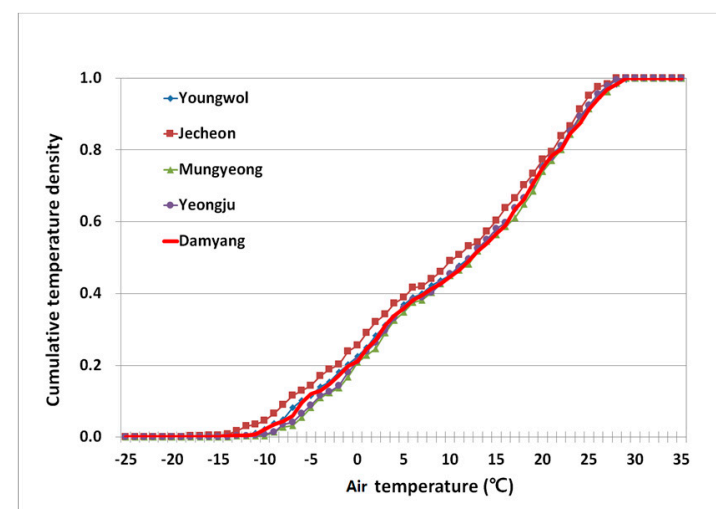

(b)

Figure 3. Accumulated air temperature and density graph for a one-year period. (a) Yangyang; (b) Danyang.

Using the above method, graph patterns of the cumulative temperature densities in 86 regions were analyzed with regard to the standard meteorological data of the adjacent cities, so that 86 regions were matched with the existing urban standard meteorological data (Table 5). 
Table 5. Derived zones of similar climate (66 zones).

\begin{tabular}{|c|c|c|c|c|c|c|c|}
\hline $\begin{array}{l}\text { Representative } \\
\text { City }\end{array}$ & Similar Climate Region & $\begin{array}{l}\text { Representative } \\
\text { City }\end{array}$ & Similar Climate Region & $\begin{array}{l}\text { Representative } \\
\text { City }\end{array}$ & Similar Climate Region & $\begin{array}{l}\text { Representative } \\
\text { City }\end{array}$ & Similar Climate Region \\
\hline Gangneung & - & Yeongdong & Gimcheon-si & Miryang & Gimhae-si, Sinan-gun & Jeju & \\
\hline Ganghwa & Gimpo-si & Yeongwol & $\begin{array}{l}\text { Danyang-gun, } \\
\text { Jeongseon-gun }\end{array}$ & Boryeong & - & Jecheon & Hongseong-gun \\
\hline Geoje & - & Yeongju & $\begin{array}{l}\text { Yeongyang-gun, } \\
\text { Yecheon-gun }\end{array}$ & Boeun & Goesan-gun & jinju & $\begin{array}{l}\text { Uiryeong-gun, } \\
\text { Haman-gun }\end{array}$ \\
\hline Geochang & Seongju-gun & Yeongcheon & Gyeongju-si & Bonghwa & - & Changwon & \\
\hline Goheung & - & Wando & - & Busan & - & Cheonan & $\begin{array}{l}\text { Gongju-si, Sejong } \\
\text { Metropolitan } \\
\text { Autonomous City, } \\
\text { Asan-si, Anseong-si, } \\
\text { Jeungpyeong-gun }\end{array}$ \\
\hline Gwangju & $\begin{array}{l}\text { Naju-si, Yeonggwang-gun, } \\
\text { Hampyeong-gun, } \\
\text { Hwasun-gun }\end{array}$ & Ulsan & Yangsan-si & Buan & Gochang-gun & Cheorwon & - \\
\hline Gumi & Sangju-si, Chilgok-gun & Uljin & - & Buyeo & $\begin{array}{l}\text { Nonsan-si, Seocheon-gun, } \\
\text { Cheongyang-gun }\end{array}$ & Cheongju & - \\
\hline Gunsan & Gimje-si & Wonju & - & Sancheong & Gurye-gun & Chuncheon & - \\
\hline Geumsan & $\begin{array}{l}\text { Gyeheung-si, Muju-gun, } \\
\text { Wanju-gun }\end{array}$ & Uiseong & $\begin{array}{l}\text { Gunwi-gun, } \\
\text { Cheongsong-gun }\end{array}$ & Seosan & $\begin{array}{c}\text { Dangjin-si, Yesan-gun, } \\
\text { Taean-gun, } \\
\text { Hongseong-gun }\end{array}$ & Chungju & - \\
\hline Namwon & $\begin{array}{l}\text { Gokseong-gun, } \\
\text { Damyang-gun, } \\
\text { Sunchang-gun, } \\
\text { Hamyang-gun }\end{array}$ & Icheon & $\begin{array}{l}\text { Gwangju-si, Yeoju-si, } \\
\text { Yongin-si, Jincheon-gun }\end{array}$ & Seoul & Guri-si, Hanam-si & Taebaek & \\
\hline Namhae & Sacheon-si, Hadong-gun & Inje & - & Sokcho & $\begin{array}{l}\text { Goseong-gun, } \\
\text { Yangyang-gun }\end{array}$ & Tongyeong & Goseong-gun \\
\hline Daegu & Gyeongsan-si & Incheon & - & Suwon & $\begin{array}{c}\text { Gwacheon-si, } \\
\text { Gwangmyeong-si, } \\
\text { Gunpo-si, Bucheon-si, } \\
\text { Seongnam-si, Siheung-si, } \\
\text { Ansan-si, Anyang-si, } \\
\text { Osan-si, Uiwang-si, } \\
\text { Pyeongtaek-si, } \\
\text { Hwaseong-si }\end{array}$ & Pyeongchang & - \\
\hline Daejeon & Okcheon-gun & Imsil & Jinan-gun & Andong & - & Pohang & - \\
\hline Dongducheon & $\begin{array}{l}\text { Goyang-si, Yangju-si, } \\
\text { Uijeongbu-si, Paju-si, } \\
\text { Pocheon-si }\end{array}$ & Jangsu & - & Yangpyeong & Namyangju-si & Hapcheon & $\begin{array}{l}\text { Goryeong-gun, } \\
\text { Changnyeong-gun }\end{array}$ \\
\hline
\end{tabular}


Table 5. Cont.

\begin{tabular}{|c|c|c|c|c|c|c|c|}
\hline $\begin{array}{l}\text { Representative } \\
\text { City }\end{array}$ & Similar Climate Region & $\begin{array}{l}\text { Representative } \\
\text { City }\end{array}$ & Similar Climate Region & $\begin{array}{l}\text { Representative } \\
\text { City }\end{array}$ & Similar Climate Region & $\begin{array}{c}\text { Representative } \\
\text { City }\end{array}$ & Similar Climate Region \\
\hline Donghae & Samcheok-si & Jangheung & Boseong-gun & Yeosu & $\begin{array}{l}\text { Gwangyang-si, } \\
\text { Suncheon-si }\end{array}$ & Haenam & $\begin{array}{c}\text { Gangiin-gun, } \\
\text { Yeongam-gun, Jindo-gun }\end{array}$ \\
\hline Mokpo & Muan-gun, Sinan-gun & Jeonju & Iksan-si & Yeongdeok & - & Hongcheon & $\begin{array}{l}\text { Gapyeong-gun, } \\
\text { Hoengseong-gun }\end{array}$ \\
\hline Mungyeong & - & Jeongeup & Jangseong-gun & & & & \\
\hline
\end{tabular}




\section{Conclusions}

The ECO2 program, which was an assessment tool of building energy in South Korea, had a limitation due to the inability to consider meteorological differences between cities, as it only reflected one of the standard meteorological data types of 13 cities. This was the data of the closest region to the location where the buildings to be assessed were located. In this study, data observed in South Korea was used as much as possible to perform more accurate building energy assessments than before by expanding the urban standard meteorological data observations to consider as much as possible the urban climate characteristics of the city where buildings were built.

(1) The standard meteorological data of 66 cities were presented through the ISO 15927-4 method, which was the international standard method, using raw data of manned and unmanned observed meteorological data for a minimum statistical period (10 years from 2001 to 2010).

(2) Among 66 standard meteorological data sets created using the ISO TRY, for regions where the horizontal global insolation data was not available, the data was employed from an adjacent region.

(3) By means of similar climate zoning using a graph pattern of the cumulative temperature density, 66 regions where the standard meteorological data was available were matched with regions where data was unavailable among $161 \mathrm{si}$, gun, and gu (minimum unit of administrative region for weather data) in South Korea.

(4) The extended standard meteorological data can provide the most approximate standard meteorological data according to the building's location to be built in South Korea, thereby increasing the accuracy of assessment results of building energy as compared to the existing standard meteorological data.

In the future, the differences in cooling and heating energy requirements in buildings should be investigated by applying both the existing meteorological data for the 13 representative cities and newly created meteorological data to the detailed building energy simulation program.

Acknowledgments: This research was supported by a grant (17CTAP-C116666-02) from the Architecture \& Urban Development Research Program funded by the Ministry of Land, Infrastructure and Transport of the Korean government.

Author Contributions: Yeweon, Kim and Hi-Kyoung, Jang analyzed the study outcomes. Ki-Hyoung, Yu conceived the concept.

Conflicts of Interest: The authors declare no conflict of interest.

\section{References}

1. IEER. Building Energy Data Book 2011; IEER: Takoma Park, MD, USA, 2011.

2. International Energy Agency. Transition to Sustainable Buildings-Strategies and Opportunities to 2050; International Energy Agency: Paris, France, 2013.

3. UNFCCC, United Nations Framework Convention on Climate Change. INDCs as submitted by Parties. 2015. Available online: http://www4.unfccc.int/Submissions/INDC/Published\%20Documents/Republic\%20of\% 20Korea/1/INDC\%20Submission\%20by\%20the\%20Republic\%20of\%20Korea\%20on\%20June\%2030.pdf (accessed on 9 August 2017).

4. Jang, M.; Kim, J.A.; Sun, S.T. Development and evaluation of laws and regulation for the Low-Carbon and Green Growth in Korea. Int. J. Urban Sci. 2010, 14, 191-206. [CrossRef]

5. Rhee, S.K.; Jang, D.C.; Chung, Y. A critical review and new policy framework of Low-Carbon, Green-Growth strategy of Korea. In Green Growth: Managing the Transition to a Sustainable Economy —Learning by Doing in East Asia and Europe; Vazquez-Brust, D.A., Sarkis, J., Eds.; Springer: Dordrecht, The Netherlands, 2012; Volume 1, pp. $27-42$.

6. International Energy Agency. Energy Policies of IEA Countries-The Republic of Korea; 2012 Review; International Energy Agency: Paris, France, 2012. 
7. Andaloro, A.P.F.; Salomone, R.; Ioppolo, G.; Andaloro, L. Energy certification of buildings: A comparative analysis of progress towards implementation in European countries. Energy Policy 2010, 38, 5840-5866. [CrossRef]

8. International Standard Organization (ISO). Energy Performance of Buildings-Calculation of Energy Use for Space Heating and Cooling; ISO: Geneva, Switzerland, 2008.

9. Hernandez, P.; Kenny, P. From net energy to zero energy buildings: Defining life cycle zero energy buildings (LC-ZEB). Energy Build. 2010, 42, 815-821. [CrossRef]

10. The Korean Solar Energy Society. 2017. Available online: http://www.kses.re.kr/data_06/list_hi.php (accessed on 14 November 2017).

11. Korea Meteorogical Administration. Available online: http:/ /www.kma.go.kr/ (accessed on 10 July 2016).

12. Taylor, J.; Davies, M.; Mavrogianni, A.; Chalabi, Z.; Biddulph, P.; Oikonomou, E.; Das, P.; Jones, B. The relative importance of input weather data for indoor overheating risk assessment in dwellings. Build. Environ. 2014, 76, 81-91. [CrossRef]

13. Hall, I.J.; Prairie, R.R.; Anderson, H.E.; Boes, E.C. Generation of a typical meteorological year. In Proceedings of the Annual Meeting of the American Section of the International Solar Energy Society, Jelgava, Latvia, 28-31 August 1978.

14. Marion, W.; Urban, K. User's Manual for TMY2s. In Derived from the 1961-1990 National Solar Radiation Data Base; National Renewable Energy Laboratory: Golden, CO, USA, 1995.

15. Wilcox, S.; Marion, W. User's Manual for TMY3 Data Sets. In Technical Report NREL/TP-581-43156; National Renewable Energy Laboratory: Golden, CO, USA, 2008.

16. American Society of Heating Refrigerating and Air-conditioning Engineers (ASHRAE). International Weather for Energy Calculations (IWEC Weather Files); User's Manual Version 1.1. Available online: https:/ /www. ashrae.org/resources--publications/bookstore/iwec2 (accessed on 13 November 2017).

17. Jylha, K.; Tietavainen, H.; Jokisalo, J.; Ilomets, S.; Hyvonen, R.; Sakub, S. Development of weighting factors for climate variables for selecting the energy reference year according to the EN ISO 15927-4 standard. Energy Build. 2012, 47, 53-60.

18. Yoo, H.C.; Park, S.H. The Review \& Evaluation of Calculation Methods for Improving of Typical Weather Data for Seou. Arch. Inst. Korea 2008, 28, 10-18.

19. ISO. Hygrothermal Performance of Buildings-Calculation and Presentation of Climatic Data-Part 4: Hourly Data for Assessing the Annual Energy Use for Heating and Cooling; EN ISO 15927-4:2005; European Committee for Standardization: Geneva, Switzerland, 2005.

20. Yoo, H.C.; Park, S.H. Comparative Analysis of Diverse Typical Weather Data Model for Building Energy Assessment. Arch. Inst. Korea 2014, 30, 215-222. [CrossRef]

21. Ministry of Interior. 2017. Available online: http:/ / www.mois.go.kr (accessed on 12 November 2017). 